\title{
Cellular allograft for multilevel stand-alone anterior cervical discectomy and fusion
}

\author{
Alec W. Gibson, PhD, ${ }^{1}$ Abdullah H. Feroze, MD, ${ }^{2}$ Madeline E. Greil, MD, ${ }^{2}$ Margaret E. McGrath, MD, ${ }^{2}$ \\ Sananthan Sivakanthan, MD, ${ }^{2}$ Gabrielle A. White-Dzuro, MD, ${ }^{3}$ John R. Williams, MD, ${ }^{2}$ \\ Christopher C. Young, MD, PhD, ${ }^{2}$ and Christoph P. Hofstetter, MD, PhD²
}

${ }^{1}$ School of Medicine and ${ }^{2}$ Department of Neurological Surgery, University of Washington, Seattle, Washington; and ${ }^{3}$ Department of Anesthesiology, Brigham and Women's Hospital, Boston, Massachusetts

OBJECTIVE Anterior cervical discectomy and fusion (ACDF) is the most common treatment for degenerative disease of the cervical spine. Given the high rate of pseudarthrosis in multilevel stand-alone ACDF, there is a need to explore the utility of novel grafting materials. In this study, the authors present a single-institution retrospective study of patients with multilevel degenerative spine disease who underwent multilevel stand-alone ACDF surgery with or without cellular allograft supplementation.

METHODS In a prospectively collected database, 28 patients who underwent multilevel ACDF supplemented with cellular allograft (ViviGen) and 25 patients who underwent multilevel ACDF with decellularized allograft between 2014 and 2020 were identified. The primary outcome was radiographic fusion determined by a 1-year follow-up CT scan. Secondary outcomes included change in Neck Disability Index (NDI) scores and change in visual analog scale scores for neck and arm pain.

RESULTS The study included 53 patients with a mean age of $53 \pm 0.7$ years who underwent multilevel stand-alone ACDF encompassing $2.6 \pm 0.7$ levels on average. Patient demographics were similar between the two cohorts. In the cellular allograft cohort, 2 patients experienced postoperative dysphagia that resolved by the 3-month follow-up. One patient developed cervical radiculopathy due to graft subsidence and required a posterior foraminotomy. At the 1-year CT, successful fusion was achieved in 92.9\% (26/28) of patients who underwent ACDF supplemented with cellular allograft, compared with $84.0 \%$ (21/25) of patients who underwent ACDF without cellular allograft. The cellular allograft cohort experienced a significantly greater improvement in the mean postoperative NDI score $(p<0.05)$ compared with the other cohort.

CONCLUSIONS Cellular allograft is a low-morbidity bone allograft option for ACDF. In this study, the authors determined favorable arthrodesis rates and functional outcomes in a complex patient cohort following multilevel stand-alone ACDF supplemented with cellular allograft.

https://thejns.org/doi/abs/10.3171/2021.3.FOCUS2150

KEYWORDS cellular allograft; ViviGen; multilevel ACDF; revision ACDF; anterior cervical discectomy and fusion

$\mathrm{D}$ EGENERATIVE cervical spondylosis is seen radiographically in approximately one-half of the US population older than 55 years. ${ }^{1-3}$ Anterior cervical discectomy and fusion (ACDF) is one of the most common approaches for treatment of cervical radiculopathy and myelopathy, with posterior approaches performed less frequently.,5 Multiple studies have shown a trend of increasing rates of surgical treatment of this condition..$^{4,6-8}$ Recent studies have suggested that the most common long-term complications of ACDF include adjacent-segment disease and pseudarthrosis, resulting in revision operations in up to $20 \%$ of cases. ${ }^{9-12}$ Furthermore, the risk of pseudarthrosis increases along with the number of levels fused, with rates ranging from $4.3 \%$ for 1 level to $56 \%$ for 4 levels. ${ }^{12}$ One study found that symptomatic adjacent-segment disease affects more than $25 \%$ of patients within 10 years of their primary operation. ${ }^{9}$ Furthermore, when adjacent-segment disease does develop, more than two-thirds of patients require further operative intervention. ${ }^{9}$

ABBREVIATIONS ACDF = anterior cervical discectomy and fusion; ASA = American Society of Anesthesiologists; NDI = Neck Disability Index; rhBMP = recombinant human bone morphogenetic protein; VAS = visual analog scale.

SUBMITTED February 1, 2021. ACCEPTED March 18, 2021.

INCLUDE WHEN CITING DOI: 10.3171/2021.3.FOCUS2150. 
With an increasing number of revision operations and high rates of pseudarthrosis in multilevel ACDF procedures, further efforts are needed to increase the arthrodesis rate of the primary surgery. Due to the high pseudarthrosis rates in these procedures, a combined anterior-posterior approach is commonly considered,${ }^{11}$ and while it is a viable option, there is a significant increase in morbidity associated with this procedure. Studies have suggested an overall complication rate of approximately $69 \%$ in the perioperative period, ${ }^{12,13}$ with postoperative dysphagia occurring in $30 \%-50 \%$ of cases. ${ }^{12,14,15}$ In patients undergoing complex revision or multilevel spine surgery, there is a dearth of biologic options available to assist with fusion. These include autograft harvest and allograft with materials such as recombinant human bone morphogenetic protein (rhBMP). However, autologous bone graft is associated with harvest site-related morbidity and increased operative time..$^{13,14}$ Additionally, rhBMP-2 has a narrow therapeutic window and is associated with potentially severe complications, ${ }^{15-21}$ resulting in an FDA warning against its use in the cervical spine. ${ }^{22}$

The cellular allograft utilized for this study (ViviGen, Johnson \& Johnson) is composed of cryopreserved viable osteogenic cells with a corticocancellous scaffold in a demineralized bone matrix, and it may help improve fusion rates in procedures with historically high failure rates. Frozen cellular allograft can be thawed in 5 minutes for rapid intraoperative use while maintaining a $96 \%$ cell viability. Furthermore, the product used for this study is enriched with osteoblasts and osteocytes as opposed to undifferentiated mesenchymal stem cells, thus minimizing the differentiation of undesirable cell types. One preliminary study showed a $100 \%$ fusion rate, improved Neck Disability Index (NDI) scores, and improved visual analog scale (VAS) scores in 21 patients who underwent multilevel spinal fusion with cellular allograft (including 8 patients who specifically underwent stand-alone ACDF). ${ }^{23}$ A subsequent study revealed a $98.7 \%$ fusion rate in 150 patients who underwent multilevel lumbar spine fusion supplemented with cellular allograft. ${ }^{24}$ However, the current evidence regarding the efficacy and safety of cellular allografts for cervical arthrodesis is limited, with no published studies comparing cellular allograft with other grafting materials. ${ }^{25}$

In this research, we aimed to explore the utility of cellular allograft in the promotion of successful arthrodesis and postoperative clinical outcomes, comparing patients who underwent multilevel ACDF augmented with cellular allograft with patients who underwent ACDF supplemented with decellularized allograft. The primary outcome was construct fusion at the 1-year follow-up as observed on CT. Secondary outcomes included construct stability observed on radiographs at the 3-month follow-up, change in NDI score, and change in neck and arm pain scores measured by the VAS.

\section{Methods}

\section{Patient Selection}

We performed an IRB-approved retrospective review of patients who underwent multilevel stand-alone ACDF procedures. All procedures were performed at our institution by a single spine surgeon between 2014 and 2020 . The indication for surgery was cervical spinal stenosis, pseudarthrosis, adjacent-segment disease, or progressive myelopathy with worsening weakness in either the upper or lower extremities. Inclusion criteria were patients aged $\geq 18$ years who underwent a multilevel stand-alone ACDF procedure and who had at least 1 year of follow-up with a CT scan completed at 1 year from the date of the surgery. Patients with incomplete medical records or lack of follow-up were excluded from the study.

\section{Surgical Procedure}

All patients underwent ACDF surgery as originally described by Robinson and Smith. ${ }^{26}$ Briefly, all patients were placed under 10 pounds of axial traction with GardnerWells tongs. Under the operative microscope, the intervertebral disc was removed with complete resection of the posterior longitudinal ligament, and posterior osteophytes were removed using the high-speed drill and Kerrison rongeurs. Structural allograft or PEEK cages were inserted into the disc spaces. For cellular allograft patients, cages were filled with approximately $1 \mathrm{ml}$ of ViviGen graft. For decellularized allograft patients, a combination of local bone shavings, decellularized allograft, and demineralized bone matrix (DBX, Johnson \& Johnson) was used. The choice of bone graft was made according to availability of cellular allograft, which required transportation from a storage facility. The construct was stabilized with an anterior titanium plate applied with 2 variable-angle screws inserted at each level within the construct.

\section{Outcomes}

Demographic information and clinical features were obtained from the medical record for all patients, including age, sex, height, BMI, symptoms at presentation, number of levels fused, smoking status, American Society of Anesthesiologists (ASA) classification, and estimated blood loss. The primary outcome of this study was construct fusion at the 1-year follow-up as observed on CT. Secondary outcomes included change in NDI score, and change in neck and arm pain scores as measured by the VAS. Postoperative functional outcome data were available for $94 \%$ of patients.

\section{Statistical Analysis}

Continuous variables are given as the mean \pm standard deviation. Comparisons between pre- and postoperative NDI and VAS scores were performed using the Wilcoxon matched-pairs signed-rank test. Comparisons between cellular and decellularized allograft groups were performed using the Mann-Whitney U-test and Fisher's exact test; $p$ $<0.05$ was considered statistically significant. Statistical analyses were performed using GraphPad Prism version 8 and Microsoft Excel software.

\section{Results}

\section{Patient Demographics}

A total of 53 patients met inclusion criteria for this 
TABLE 1. Patient demographics for patients who underwent multilevel ACDF

\begin{tabular}{lccc}
\hline & $\begin{array}{c}\text { Cellular } \\
\text { Allograft } \\
\text { Cohort }\end{array}$ & $\begin{array}{c}\text { Decellularized } \\
\text { Allograft } \\
\text { Cohort }\end{array}$ & $\begin{array}{c}p \\
\text { Value }\end{array}$ \\
\hline Sex, $\mathrm{n}(\%)$ & & & $0.173^{*}$ \\
\hline Male & $10(35.7)$ & $14(56.0)$ & \\
\hline Female & $18(64.3)$ & $11(44.0)$ & \\
\hline Mean age, yrs & $56.3 \pm 10.2$ & $55.0 \pm 12.7$ & $0.835 \dagger$ \\
\hline Mean height, $m$ & $1.7 \pm 0.1$ & $1.7 \pm 0.1$ & $0.159 \dagger$ \\
\hline Mean BMl & $28.9 \pm 5.7$ & $31.4 \pm 5.2$ & $0.121 \dagger$ \\
\hline Smoking status, $n(\%)$ & & & $0.730^{*}$ \\
\hline Never smoked & $12(42.9)$ & $9(36.0)$ & \\
\hline Previous smoker & $14(50.0)$ & $15(60.0)$ & \\
\hline Current smoker & $2(7.1)$ & $1(4.0)$ & \\
\hline Mean ASA classification & $2.4 \pm 0.6$ & $2.7 \pm 0.6$ & $0.069 \dagger$ \\
\hline Mean preop NDI score & $39.6 \pm 16.0$ & $42.4 \pm 14.3$ & $0.792 \dagger$ \\
\hline Mean preop neck VAS score & $5.0 \pm 3.0$ & $6.6 \pm 1.4$ & $0.100 \dagger$ \\
\hline Mean preop arm VAS score & $4.5 \pm 3.1$ & $2.8 \pm 2.9$ & $0.112 \dagger$ \\
\hline
\end{tabular}

Mean values are presented as the mean \pm SD.

*By Fisher's exact test.

$\dagger$ By Mann-Whitney U-test.

study at our institution from 2014 to 2020, including 28 patients who underwent multilevel ACDF augmented with cellular allograft and 25 patients who underwent ACDF supplemented with decellularized allograft. Patient demographics of the 2 cohorts are shown in Table 1 . There were no statistically significant differences for all preoperative demographics between the groups except for a trend toward a higher rate of former smokers in the decellularized allograft cohort.

A total of 8 patients $(28.6 \%)$ in the cellular allograft cohort had undergone a previous anterior cervical spine surgery; 3 of these patients presented with previous pseudarthrosis following ACDF, and 2 patients presented with worsening symptoms following disc arthroplasty. Of the 8 patients who had a history of previous surgery, 1 had concurrent adjacent-segment disease and 1 presented with a significant prevertebral mass that caused preoperative dysphagia. All 28 patients in the cellular allograft cohort presented with complaints of progressive myelopathy with both upper- and lower-extremity weakness. Two (7.1\%) of these patients had ossification of the posterior longitudinal ligament, and 3 patients (10.7\%) had partial corpectomies at the time of the procedure. All procedures were performed between the levels of C3 and C7. Structural allograft spacers were used in most patients, and $10.7 \%$ received PEEK cages. For each patient, $1.5 \mathrm{ml}$ of cellular allograft was placed within each spacer prior to their incorporation into the construct. In the cellular allograft cohort, an average of $2.6 \pm 0.8$ levels were fused. The mean estimated blood loss was $157.0 \pm 190.5 \mathrm{ml}$.

Two patients $(8.0 \%)$ in the decellularized allograft cohort had undergone previous ACDF and presented with adjacent-level foraminal stenosis. Three patients (12.0\%) had a partial corpectomy at the time of surgery. Demo-
TABLE 2. Postoperative outcomes for patients who underwent multilevel ACDF

\begin{tabular}{lccc}
\hline & $\begin{array}{c}\text { Cellular } \\
\text { Allograft } \\
\text { Cohort }\end{array}$ & $\begin{array}{c}\text { Decellularized } \\
\text { Allograft } \\
\text { Cohort }\end{array}$ & $\begin{array}{c}p \\
\text { Value }\end{array}$ \\
\hline Mean no. of levels fused & $2.6 \pm 0.8$ & $2.4 \pm 0.7$ & $0.307^{*}$ \\
\hline Fusion success rate, $\mathrm{n}(\%)$ & $26 / 28(92.9)$ & $21 / 25(84.0)$ & $0.404 \dagger$ \\
\hline Mean postop NDI score & $16.0 \pm 10.9$ & $33.1 \pm 20.6$ & $0.034^{*}$ \\
\hline Mean change in NDI score & $-23.5 \pm 13.7$ & $-9.3 \pm 16.6$ & $0.031^{*}$ \\
\hline Mean postop neck VAS score & $3.3 \pm 2.5$ & $3.2 \pm 2.8$ & $0.851^{*}$ \\
\hline $\begin{array}{l}\text { Mean change in neck VAS } \\
\text { score }\end{array}$ & $-1.7 \pm 2.6$ & $-3.4 \pm 2.9$ & $0.208^{*}$ \\
\hline Mean postop arm VAS score & $3.0 \pm 2.4$ & $1.4 \pm 2.3$ & $0.057^{*}$ \\
\hline $\begin{array}{l}\text { Mean change in arm VAS } \\
\text { score }\end{array}$ & $-1.6 \pm 3.0$ & $-1.3 \pm 3.6$ & $0.946^{*}$ \\
\hline
\end{tabular}

Mean values are presented as the mean \pm SD.

* By Mann-Whitney U-test.

$\dagger$ By Fisher's exact test.

graphics for these patients are shown in Table 1. For patients in the decellularized allograft cohort, all procedures were performed between the levels of C3 and C7. Approximately half of the patients had structural allograft spacers, and 12 patients $(48.0 \%)$ received PEEK cages. Thus, the decellularized allograft cohort had a significantly higher rate of PEEK cage use compared with the cellular allograft cohort $(\mathrm{p}<0.01)$. Constructs included an average of $2.4 \pm 0.7$ levels, and the average estimated blood loss was $101.4 \pm 94.1 \mathrm{ml}$.

\section{Clinical Outcomes for Patients in the Cellular Allograft Cohort}

Postoperative outcomes are shown in Table 2. After surgery, 4 patients (14.3\%) in the cellular allograft cohort experienced neck swelling. Three patients $(10.7 \%)$ had dysphagia following the procedure; however, 1 of these patients had a large prevertebral mass that formed around material from disintegrating hardware and caused swallowing dysfunction at the preoperative baseline. Dysphagia was completely resolved at the 3-month follow-up for all patients. One patient $(5.0 \%)$ required surgical exploration for postoperative foraminal stenosis at adjacent levels to the construct 7 months after the initial surgery. At the 3-month follow-up, $96.4 \%$ of patients receiving cellular allograft had stable constructs on upright cervical radiographs, and at the 1-year follow-up, $92.8 \%$ of these patients demonstrated successful fusion of the cervical spine on CT (Fig. 1). Both patients with pseudarthrosis had a history of nonunion from a previous ACDF. There was a significant improvement in the mean NDI score from 39.5 \pm 16.0 to $16.0 \pm 10.9(\mathrm{p}=0.0002)$. At the 1 -year followup, the mean neck VAS score had significantly decreased from $5.0 \pm 3.0$ to $3.3 \pm 2.5(\mathrm{p}=0.014)$ and the mean arm VAS score had significantly decreased from $4.5 \pm 3.1$ to $3.0 \pm 2.4(\mathrm{p}=0.037)$. There were no differences in postoperative NDI or VAS score changes based on the numbers of levels fused ( $p=0.945$ for NDI, $p=0.374$ for neck VAS pain, and $p=0.265$ for arm VAS pain). 

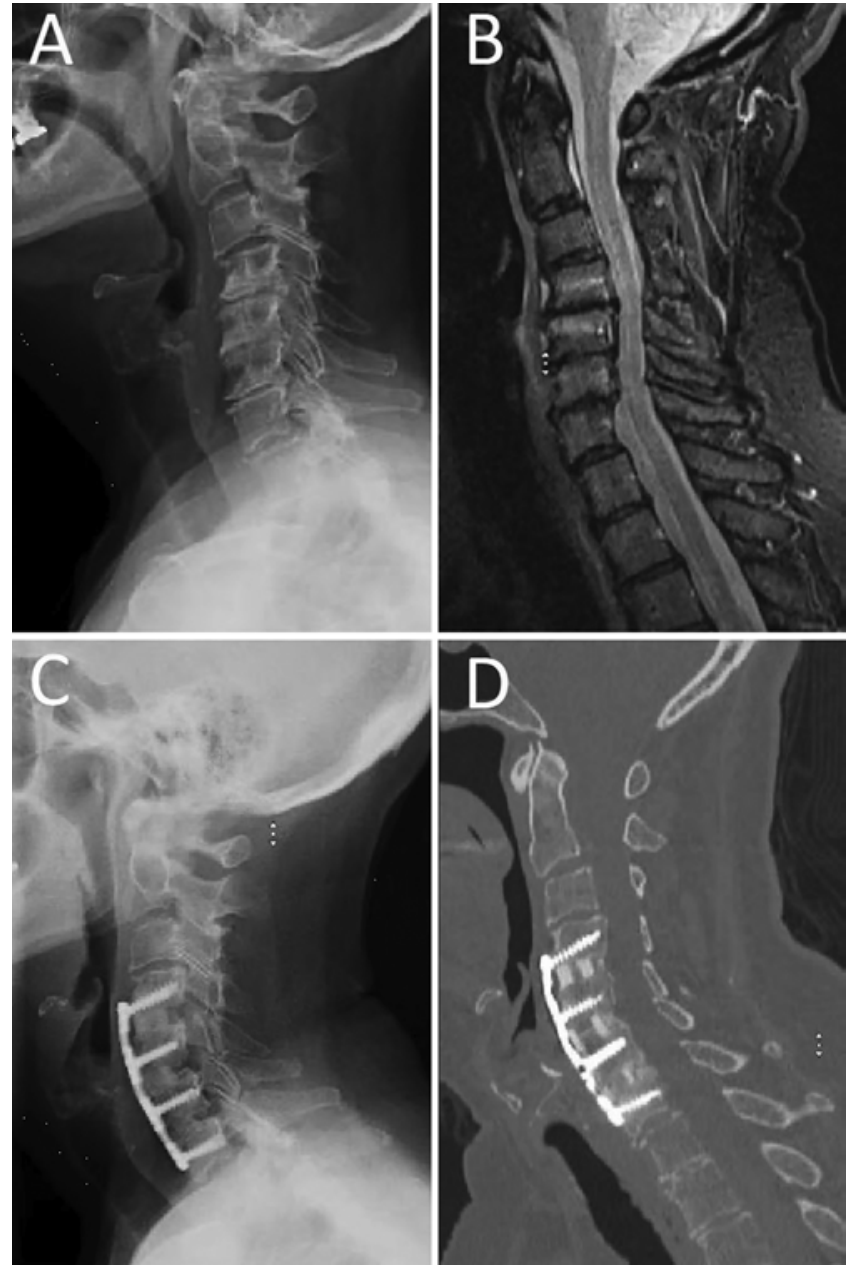

FIG. 1. Representative images before and after multilevel ACDF with cellular allograft. $\mathbf{A}$ and $\mathbf{B}$ : Preoperative cervical spine radiograph (A) and preoperative MR image (B) demonstrating cervical spinal stenosis. C: Radiograph obtained 3 months postoperatively, showing hardware stability. D: CT scan obtained 1 year postoperatively, demonstrating successful fusion of the cervical spine.

\section{Clinical Outcomes for Patients With ACDF Supplemented With Decellularized Allograft}

In the cohort of patients who underwent ACDF supplemented with decellularized allograft, 1 patient (4.0\%) required repeat surgery for graft subsidence and foraminal stenosis, 1 patient experienced an epidural hematoma requiring surgical evacuation and posterior fusion, 1 patient experienced long-term miosis and mydriasis secondary to Horner's syndrome, and 1 patient required additional surgery for adjacent-segment disease. Three patients (12.0\%) experienced postoperative dysphagia that remained present at the 3-month follow-up; however, 1 of these patients had anterior osteophytes that caused preoperative dysphagia. Finally, 21 of 25 patients $(84.0 \%)$ demonstrated successful fusion of the cervical spine on CT at the 1-year follow-up, while 1 patient (4.0\%) showed pseudarthrosis at 2 of 3 levels. An additional 3 patients also demonstrated evidence of pseudarthrosis, but all were managed conservatively with the use of a bone stimulator without the need for additional surgery. Half of the patients with nonunions had structural allograft and the other half had PEEK cages.

As shown in Table 2, both cellular allograft and decellularized allograft cohorts had similar numbers of levels fused. For patients who received cellular allograft, 92.8\% experienced successful fusion after 1 year, compared with $84.0 \%$ of patients who received decellularized allograft, which did not reach a statistically significant difference $(p=0.404)$. However, the cellular allograft cohort experienced a significantly greater improvement in their mean postoperative NDI score $(\mathrm{p}<0.05)$ compared with the decellularized allograft cohort. Postoperative VAS outcomes for neck and arm pain for both groups were not significantly different (Table 2).

\section{Discussion}

This study has demonstrated the safety and efficacy of cellular allograft for use in multilevel ACDF procedures, supporting successful fusion of the construct at the 1-year follow-up with minimal complications for the 28 patients receiving cellular allograft. While 1 patient did require a repeat surgery, it was for graft subsidence and nerve root entrapment, not for pseudarthrosis. Imaging and intraoperative exploration in this patient showed fusion of the construct at all levels, and there was improvement in the NDI score following surgery.

While autologous bone graft, including iliac crest and fibular autografts, is considered the gold standard, ${ }^{26-28}$ donor site morbidity coupled with increased operative time has led surgeons to consider alternatives, including cadaveric bone and demineralized bone matrix as allografts. ${ }^{13,14,25}$ In studies in which autograft has been compared with allograft, no statistically significant difference in fusion rates has been shown. Samartzis et al. specifically examined fusion rates in multilevel and single-level ACDFs in which either allograft or autograft was used..$^{29,30}$ They found no difference in rates of fusion between autograft and allograft in both single-level and multilevel fusions. While previous studies have suggested the use of rhBMP-2 as a biologic allograft to assist with fusion rates, ${ }^{31}$ more recent studies have shown an increase in postoperative complications associated with its use. . $^{15,17-21}$ The rate of complications was recognized by an FDA warning against the use of rhBMP-2 in cervical spine fusions..$^{17}$ In current spine practice, there is a paucity of biologics that can be used to augment ACDFs.

Multilevel stand-alone ACDF has a pseudarthrosis rate of approximately $20 \% .^{9}$ Previous papers have suggested that when fusing more than 3 cervical segments, a combined anterior-posterior approach should be employed due to the high rate of graft failure and pseudarthrosis. ${ }^{32}$ While the combined procedure is a viable option, it is not without significant risks. Studies have found a rate of dysphagia between $30 \%$ and $50 \%$ in the immediate postoperative period. ${ }^{33-35}$ Postoperative dysphagia leads to a statistically significant increase in hospital length of stay. ${ }^{34,35}$ Other complications of the combined procedure include airway edema requiring prolonged intubation and decreased range of motion, and the overall complication rate of a combined anterior-posterior procedure has been 
quoted to be as high as $69 \%$ in the perioperative period, which decreases to approximately $5 \%$ in the long term. ${ }^{33,36}$ Similarly, cost and healthcare expenditure are also important to consider when examining the utility of a multilevel stand-alone ACDF procedure versus a combined anteriorposterior cervical approach.

The current study represents the largest cohort of patients receiving cellular allograft for multilevel ACDF to date. We demonstrated a $92.8 \%(26 / 28)$ fusion rate at the 1-year follow-up for 28 patients who received cellular allograft, compared with an $84.0 \%(21 / 25)$ fusion rate for 25 patients who received decellularized allograft. The results suggest that cellular allograft is both safe, with a low rate of postoperative complications, and effective, as demonstrated in a favorable rate of arthrodesis in this challenging patient cohort. Our study also showed significant improvement in NDI scores, as well as postoperative neck and arm pain scores, compared with preoperative values. However, there are statistical and design limitations to the study, including the retrospective, single-surgeon design and the small patient cohort, resulting in part from the inclusion criteria of a 1-year postoperative CT scan to assess fusion. In addition, the use of PEEK cages was significantly higher in the decellularized allograft cohort. The use of PEEK cages has been associated with higher rates of pseudarthrosis and, as such, represents a possible independent risk factor for fusion failure. ${ }^{37,38}$

\section{Conclusions}

Cellular allograft is a low-morbidity bone allograft option for complex, multilevel ACDF. Our study shows successful fusion of the construct with minimal postoperative complications. Utilization of a safe and effective biologic bone graft can allow for fusion without the need for a posterior construct for further stabilization.

\section{Acknowledgments}

We appreciate the assistance of Sharon Durfy, $\mathrm{PhD}$, with manuscript preparation.

\section{References}

1. Hughes JT. The pathology of vascular disorders of the spinal cord. Paraplegia. 1965;2:207-213.

2. Irvine DH, Foster JB, Newell DJ, Klukvin BN. Prevalence of cervical spondylosis in a general practice. Lancet. 1965;1(7395):1089-1092.

3. Pallis C, Jones AM, Spillane JD. Cervical spondylosis; incidence and implications. Brain. 1954;77(2):274-289.

4. Witiw CD, Smieliauskas F, O'Toole JE, et al. Comparison of anterior cervical discectomy and fusion to posterior cervical foraminotomy for cervical radiculopathy: utilization, costs, and adverse events 2003 to 2014. Neurosurgery. 2019;84(2):413-420.

5. Saifi C, Cazzulino A, Park C, et al. National trends for primary and revision lumbar disc arthroplasty throughout the United States. Global Spine J. 2018;8(2):172-177.

6. Mok JK, Sheha ED, Samuel AM, et al. Evaluation of current trends in treatment of single-level cervical radiculopathy. Clin Spine Surg. 2019;32(5):E241-E245.

7. Patil PG, Turner DA, Pietrobon R. National trends in surgical procedures for degenerative cervical spine disease: 19902000. Neurosurgery. 2005;57(4):753-758.
8. Wang MC, Kreuter W, Wolfla CE, et al. Trends and variations in cervical spine surgery in the United States: Medicare beneficiaries, 1992 to 2005. Spine (Phila Pa 1976). 2009;34(9):955-963.

9. Fraser JF, Härtl R. Anterior approaches to fusion of the cervical spine: a metaanalysis of fusion rates. J Neurosurg Spine. 2007;6(4):298-303.

10. Hilibrand AS, Carlson GD, Palumbo MA, et al. Radiculopathy and myelopathy at segments adjacent to the site of a previous anterior cervical arthrodesis. J Bone Joint Surg Am. 1999;81(4):519-528.

11. van Eck CF, Regan $C$, Donaldson WF, et al. The revision rate and occurrence of adjacent segment disease after anterior cervical discectomy and fusion: a study of 672 consecutive patients. Spine (Phila Pa 1976). 2014;39(26):2143-2147.

12. Epstein NE. Review of risks and complications of extreme lateral interbody fusion (XLIF). Surg Neurol Int. 2019;10:237.

13. Heneghan HM, McCabe JP. Use of autologous bone graft in anterior cervical decompression: morbidity \& quality of life analysis. BMC Musculoskelet Disord. 2009;10:158.

14. Wright IP, Eisenstein SM. Anterior cervical discectomy and fusion without instrumentation. Spine (Phila Pa 1976). 2007;32(7):772-775.

15. Burkus JK, Dryer RF, Arnold PM, Foley KT. Clinical and radiographic outcomes in patients undergoing single-level anterior cervical arthrodesis: a prospective trial comparing allograft to a reduced dose of rhBMP-2. Clin Spine Surg. 2017;30(9):E1321-E1332.

16. Hofstetter CP, Hofer AS, Levi AD. Exploratory meta-analysis on dose-related efficacy and morbidity of bone morphogenetic protein in spinal arthrodesis surgery. J Neurosurg Spine. 2016;24(3):457-475.

17. Jain A, Hassanzadeh $\mathrm{H}$, Strike SA, et al. rhBMP use in cervical spine surgery: associated factors and in-hospital complications. J Bone Joint Surg Am. 2014;96(8):617-623.

18. Shields LB, Raque GH, Glassman SD, et al. Adverse effects associated with high-dose recombinant human bone morphogenetic protein-2 use in anterior cervical spine fusion. Spine (Phila Pa 1976). 2006;31(5):542-547.

19. Smucker JD, Rhee JM, Singh K, et al. Increased swelling complications associated with off-label usage of rhBMP-2 in the anterior cervical spine. Spine (Phila Pa 1976). 2006;31(24):2813-2819.

20. Vaidya R, Sethi A, Bartol S, et al. Complications in the use of rhBMP-2 in PEEK cages for interbody spinal fusions. $J$ Spinal Disord Tech. 2008;21(8):557-562.

21. Vaidya R, Weir R, Sethi A, et al. Interbody fusion with allograft and rhBMP-2 leads to consistent fusion but early subsidence. J Bone Joint Surg Br. 2007;89(3):342-345.

22. Food and Drug Administration. FDA Public Health Notification: Life-Threatening Complications Associated with Recombinant Human Bone Morphogenetic Protein in Cervical Spine Fusion. Issued July 1, 2008. Accessed April 11, 2021. http://www.tccortho.com/pdf/FDAPublic\%20Health\%20 Note.pdf

23. Divi SN, Mikhael MM. Use of allogenic mesenchymal cellular bone matrix in anterior and posterior cervical spinal fusion: a case series of 21 patients. Asian Spine $J$. 2017;11(3):454-462.

24. Hall JF, McLean JB, Jones SM, et al. Multilevel instrumented posterolateral lumbar spine fusion with an allogeneic cellular bone graft. J Orthop Surg Res. 2019;14(1):372.

25. Hsieh PC, Buser Z, Skelly AC, et al. Allogenic stem cells in spinal fusion: a systematic review. Global Spine J. 2019;9(1) (suppl):22S-38S.

26. Robinson RA, Smith GW. Anterolateral cervical disc removal and interbody fusion for cervical disc syndrome. Bull Johns Hopkins Hosp. 1955;96:223-224. 
27. Cloward RB. The anterior approach for removal of ruptured cervical disks. J Neurosurg. 1958;15(6):602-617.

28. Sonntag VK, Han PP, Vishteh AG. Anterior cervical discectomy. Neurosurgery. 2001;49(4):909-912.

29. Samartzis D, Shen FH, Goldberg EJ, An HS. Is autograft the gold standard in achieving radiographic fusion in one-level anterior cervical discectomy and fusion with rigid anterior plate fixation? Spine (Phila Pa 1976). 2005;30(15):1756-1761.

30. Samartzis D, Shen FH, Matthews DK, et al. Comparison of allograft to autograft in multilevel anterior cervical discectomy and fusion with rigid plate fixation. Spine $J$. 2003;3(6):451-459.

31. Baskin DS, Ryan P, Sonntag V, et al. A prospective, randomized, controlled cervical fusion study using recombinant human bone morphogenetic protein-2 with the CORNERSTONE-SR allograft ring and the ATLANTIS anterior cervical plate. Spine (Phila Pa 1976). 2003;28(12):1219-1225.

32. Mummaneni PV, Burkus JK, Haid RW, et al. Clinical and radiographic analysis of cervical disc arthroplasty compared with allograft fusion: a randomized controlled clinical trial. $J$ Neurosurg Spine. 2007;6(3):198-209.

33. Hart RA, Tatsumi RL, Hiratzka JR, Yoo JU. Perioperative complications of combined anterior and posterior cervical decompression and fusion crossing the cervico-thoracic junction. Spine (Phila Pa 1976). 2008;33(26):2887-2891.

34. Chen CJ, Saulle D, Fu KM, et al. Dysphagia following combined anterior-posterior cervical spine surgeries. J Neurosurg Spine. 2013;19(3):279-287.

35. Reinard KA, Cook DM, Zakaria HM, et al. A cohort study of the morbidity of combined anterior-posterior cervical spinal fusions: incidence and predictors of postoperative dysphagia. Eur Spine J. 2016;25(7):2068-2077.

36. Schultz KD Jr, McLaughlin MR, Haid RW Jr, et al. Singlestage anterior-posterior decompression and stabilization for complex cervical spine disorders. J Neurosurg. 2000;93(2) (suppl):214-221.

37. Nichols NM, Jamieson A, Wang M, et al. Characterizing the fusion order and level-specific rates of arthrodesis in 3-level anterior cervical discectomy and fusion: a radiographic study. J Clin Neurosci. 2020;81:328-333.
38. Teton ZE, Cheaney B, Obayashi JT, Than KD. PEEK interbody devices for multilevel anterior cervical discectomy and fusion: association with more than 6-fold higher rates of pseudarthrosis compared to structural allograft. J Neurosurg Spine. 2020;32(5):696-702.

\section{Disclosures}

Dr. Hofstetter: consultant for Joimax, Globus Medical, Johnson \& Johnson, and Innovasis.

\section{Author Contributions}

Conception and design: Feroze, White-Dzuro, Hofstetter. Acquisition of data: Gibson, Greil, McGrath, Sivakanthan, Williams, Young. Analysis and interpretation of data: Greil, McGrath. Drafting the article: Feroze, Gibson, Greil, White-Dzuro, Williams, Young. Critically revising the article: Feroze, Gibson, Greil, White-Dzuro, Williams, Young. Reviewed submitted version of manuscript: Feroze, Gibson, Greil, McGrath, Sivakanthan, Williams, Young, Hofstetter. Approved the final version of the manuscript on behalf of all authors: Feroze. Statistical analysis: Feroze, Gibson, Hofstetter. Administrative/ technical/material support: Hofstetter. Study supervision: Hofstetter.

\section{Correspondence}

Abdullah H. Feroze: University of Washington Medical Center, Seattle,WA. aferoze@uw.edu. 